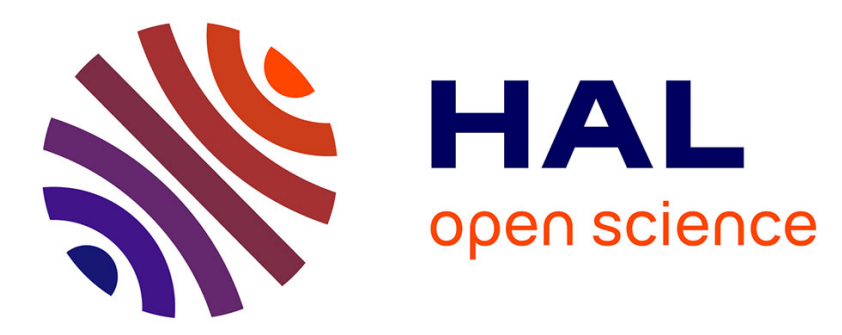

\title{
Antioxidant supplementation accelerates cachexia development by promoting tumor growth in C26 tumor-bearing mice
}

Mohamad Assi, Frédéric Derbré, Luz Lefeuvre-Orfila, Amélie Rébillard

\section{To cite this version:}

Mohamad Assi, Frédéric Derbré, Luz Lefeuvre-Orfila, Amélie Rébillard. Antioxidant supplementation accelerates cachexia development by promoting tumor growth in C26 tumor-bearing mice. Free Radical Biology and Medicine, 2016, 91, pp.204-214. 10.1016/j.freeradbiomed.2015.12.019 . hal-01255843

HAL Id: hal-01255843

https://hal-univ-rennes1.archives-ouvertes.fr/hal-01255843

Submitted on 25 Mar 2016

HAL is a multi-disciplinary open access archive for the deposit and dissemination of scientific research documents, whether they are published or not. The documents may come from teaching and research institutions in France or abroad, or from public or private research centers.
L'archive ouverte pluridisciplinaire HAL, est destinée au dépôt et à la diffusion de documents scientifiques de niveau recherche, publiés ou non, émanant des établissements d'enseignement et de recherche français ou étrangers, des laboratoires publics ou privés. 


\title{
Antioxidant supplementation accelerates cachexia development by promoting tumor growth in C26 tumor-bearing mice
}

Mohamad Assi ${ }^{1 *}$, Frédéric Derbré ${ }^{1 *}$, Luz Lefeuvre-Orfila ${ }^{1}$ and Amélie Rébillard ${ }^{1}$

${ }^{1}$ EA1274 Laboratory "Movement, Sport and health Sciences" M2S, University of Rennes 2-ENS Rennes, Bruz, France

*: Co-first authors who contributed equally to this study

Running title: antioxidants aggravate $\mathrm{C} 26$-induced cachexia

Corresponding author: Amélie Rébillard, Email: amelie.rebillard@univ-rennes2.fr Tel: (33) (0)290091587

\begin{abstract}
More than $50 \%$ of patients with advanced stages of colon cancer suffer from progressive loss of skeletal muscle, called cachexia, resulting in reduced quality of life and shortened survival. It is becoming evident that reactive oxygen species (ROS) regulate pathways controlling skeletal muscle atrophy. Herein we tested the hypothesis that antioxidant supplementation could prevent skeletal muscle atrophy in a model of cachectic Colon 26 (C26) tumor-bearing mice. Sevenweek-old BALB/c mice were subcutaneously inoculated with colon 26 (C26) cancer cells or PBS. Then C26-mice were daily gavaged during 22 days either with PBS (vehicle) or an antioxidant cocktail whose composition is close to that of commercial dietary antioxidant supplements (rich in catechins, quercetin and vitamin C). We found that antioxidants enhanced weight loss and caused premature death of mice. Antioxidants supplementation failed to prevent (i) the increase in plasma TNF- $\alpha$ levels and systemic oxidative damage (ii) skeletal muscle
\end{abstract}


atrophy and (iii) activation of the ubiquitin-proteasome system (MuRF-1, MAFbx and polyubiquitinated proteins). Accordingly, immunohistological staining for Ki-67 and the expression of cell cycle inhibitors demonstrated that tumor of supplemented mice developed faster with a concomitant decrease in oxidative damage. Previous studies have shown that the use of catechins and quercetin separately can improve the musculoskeletal function in cachectic animals. However, our results indicate that the combination of these antioxidants reduced survival and enhanced cachexia in C26-mice.

\section{Keywords:}

muscle wasting, TNF- $\alpha$, myostatin, tumor growth, oxidative stress

\section{INTRODUCTION}

Cachexia is a multifactorial syndrome and a complex metabolic disorder that manifests mainly in patients with diabetes, acquired immune deficiency syndrome (AIDS) and cancer. It is characterized by a continuous loss of muscle mass with or without depletion of adipose tissue [1]. Contrary to anorexia, in which adipose tissue is mainly affected but rarely the muscle compartment, conventional and single-nutritional intervention failed to prevent total weight loss and/or restore lean body mass in cancer cachexia [2]. Patients with advanced stages of colon cancer are mainly affected by cachexia, which accounts for more than $20 \%$ of mortality in total cancer patients [3]. Muscle atrophy is one of the most significant clinical events in cancer cachexia that negatively impact patient's quality of life and strongly reduce anti-cancer treatment 
efficiency [4]. Cachexia-induced muscle atrophy (CIMA) is often associated with psychosocial effects due to functional impairment and a dramatically reduced physical activity in cachectic patients [5]. Therefore, the management of cancer cachexia, notably muscle atrophy, represents a real challenge and a major issue for researchers and clinicians in the biomedical field.

Disease-related muscle atrophy have received much attention during the past decade and several studies have been devoted to understand the pathophysiology and explore the underlying molecular mechanisms involved in the wasting process. Muscle atrophy is mainly due to an increase in protein catabolism associated with hypo-anabolism, resulting in a net decrease in overall muscle mass [6]. High circulating levels of tumor-derived factors (e.g. Tumor Necrosis Factor- $\alpha$ and Interleukin-6) and some Transforming Growth Factor-beta (TGF- $\beta$ ) family ligands (e.g. myostatin and activin), are responsible for the inhibition of the anabolic/hypertrophic, Phosphoinositide 3-kinase (PI3K)-Akt pathway and subsequently the depression in protein synthesis rate $[7,8]$. On the other hand, these cytokines, trigger the activation of catabolic/atrophic upstream signaling cascades (e.g. Nuclear Factor- $\mathrm{B} / \mathrm{AP}-1$ ), leading to the transcriptional activation of two muscle-specific E3 ubiquitin-ligases, known as, Muscle Ring finger protein-1 (MuRF-1) and Muscle Atrophy F-box (MAFbx) [9, 10]. Sarcomeric proteins destined to degradation are tagged with polyubiquitin chain, thanks to MuRF-1 and MAFbx, prior the entry into the proteasome core, where they undergo degradation into small peptide fragments. Hyper-activation of the ubiquitin-proteasome proteolytic system is common in CIMA and is mainly responsible for the high breakdown of myofibrillar proteins [11]. 
Currently, it is well established and recognized that muscle wasting is intimately linked to oxidative stress (OS) in various conditions including disuse, ageing and spinal cord injury [12, 13]. It seems that OS is also implicated in cachexia pathogenesis, since oxidative damage markers (e.i. carbonyls proteins) were increased in the skeletal muscle of cachectic patients with lung cancer and were positively correlated with muscle proteolysis [14]. Furthermore, Reactive Oxygen Species (ROS) have been proposed to act as a second messenger to activate the ubiquitin-proteasome system in an in vitro model of muscle atrophy [15]. Actually, there is growing evidence that sarcopenia or disuse-induced catabolic state in the muscles of rodents models, could be prevented or delayed by the use of different types and doses of antioxidants such as Vitamin E, Resveratrol, Cystein-based antioxidants and Allopurinol [16-19]. Since a broad range of ROS is involved in cachexia-related muscle atrophy pathogenesis, we suppose that the use of a combination of antioxidants could be more valuable to target a large spectrum of these species and limit their detrimental activities. Herein, we tested our hypothesis in a model of colon 26 (C26) tumor-bearing mice supplemented or not with a mixture of antioxidants containing mainly, catechins, curcumin, quercetin and vitamin C.

\section{MATERIALS AND METHODS}

\section{Animals care and protocol}

All experiments were approved by the Regional Ethics Committee for Animal Experimentation of Brittany ( $\left.{ }^{\circ} \mathrm{R}-2012-\mathrm{AR}-01\right)$ and conducted in accordance with the current ethical standards of 
the European Community (Directive 2010/63/EU). Seven-week-old male Balb/c mice were obtained from Janvier Labs (Le Genest Saint Isle, France) and housed in the Animal Care Facility of the laboratory "Movement, Sport and health Sciences" accredited for live animal experimentation $\left(\mathrm{N}^{\circ} \mathrm{A} 35-047-34\right.$, delivered by the Department of Veterinary Services, French Ministry of Agriculture). Mice were maintained on a 12:12-h dark-light cycle. Water was available ad libitum and standard laboratory chow was provided, changed and monitored daily. The animals were divided into three experimental groups: control group that received a daily supplement of $250 \mu 1$ of PBS ( $n=10$ ); C26 tumor-bearing group that received $250 \mu 1$ of PBS $(\mathrm{n}=10)$; and C26 tumor-bearing group that was daily supplemented with an antioxidant mixture rich in catechins, curcumin, quercetin and vitamin $\mathrm{C}(81.5 \mathrm{mg} / \mathrm{kg}$ of body weight $)$ dissolved in $350-500 \mu 1$ of PBS $(n=10)$. The volume of the daily supplement received by each mouse in this group was daily adjusted with body weight change. All treatments were administrated by oral gavage. The composition of the antioxidant cocktail is presented in Table 1. Twenty two days after inoculation of C26 cells or when mice have lost more than $20 \%$ of body weight, animals were anesthetized with a ketamine-xylazine-butorphanol cocktail. Soleus, Extensor digitorum longus (EDL), rectus femoris, gastrocnemius (Gas) muscles and tumor were weighed and immediately frozen in liquid nitrogen or fixed in 4\%-paraformaldehyde (PFA). Venous blood was collected into EDTA tubes and centrifuged $\left(1500 \mathrm{~g}, 10 \mathrm{~min}, 4^{\circ} \mathrm{C}\right)$ for plasma collection.

\section{Culture of C26 cell line and inoculation}


Frozen C26 colon cancer cells were obtained from Cell Lines Service (CLS, Eppelheim, Germany). The murine tumor cells were maintained in a humidified atmosphere at $37^{\circ} \mathrm{C}$ and $5 \%$ CO2 and cultured in RPMI 1640 medium supplemented with $10 \%$ fetal bovine serum (FBS), 2 mM L-glutamine (Life technologies, Saint Aubin, France). Cells were collected using 0.25\% trypsin-EDTA. Before the injection of C26 cells into mice (day 1), cells were counted using a hemocytometer, pelleted via centrifugation $\left(500 \mathrm{~g}, 5 \mathrm{~min}, 25^{\circ} \mathrm{C}\right)$ and resuspended at $1 \times 10^{6} \mathrm{C} 26$ cells/ml of sterilized PBS. Mice were shaved on the dorsal side and given a subcutaneous injection of either $1 \times 10^{6} \mathrm{C} 26$ cells suspended in $100 \mu \mathrm{l}$ of sterilized PBS or $100 \mu 1$ of sterilized PBS only (control) [20,21]. Body mass was monitored daily after inoculation.

\section{Determination of cachexia symptoms severity}

Mice were classified as having mild, moderate, or severe cachexia based on their body mass and gastrocnemius muscle mass. C26 tumor-bearing mice were categorized as having mild cachexia, if both variables were within 1 SD (Standard Deviation) of the mean of control mice. Mice with severe cachexia were $>2$ SDs away from the mean of control mice [22].

\section{Wire hang test}

At the beginning of the protocol, 10 days and 22 days after inoculation, a wire test was used to assess whole body force. Mice were placed on top of a wire cage lid that was shaken gently 3 times, causing the mouse to grip the wire. Then, the wire cage lid was inverted. Three trials per animal were performed for each evaluation and the best time of latency was retained to calculate the holding impulse [23]. 


\section{Histological analysis}

EDL muscle or tumor samples were $24 \mathrm{~h}$ PFA-fixed and paraffin-embedded in blocks. Serial transverse sections of $4 \mu \mathrm{m}$ were obtained from each sample using a LEICA microtome and were mounted on glass slides, three cuts in each. The cuts were performed in the wider part of the tissues. Subsequently, EDL sections were stained for reticulin using the Gomori method to measure muscle fibers diameter and tumor sections were stained for $\mathrm{Ki}-67$ in order to determine the percentage of tumor proliferating cells. All the histological sections were scanned $(20 \times$ objective and 40× magnification). The minimal Feret's diameter of muscle fiber was determined using the Image $\mathrm{J}$ software. Mean fiber diameter for each muscle was determined from at least 150 fibers per muscle. For ki-67 quantification four images were taken per section and the number of ki-67 positive nuclei was counted using NDP image software.

\section{RNA isolation and RT-qPCR}

Total RNA were extracted from Gas muscles and tumor tissues using Trizol ${ }^{\circledR}$ reagent according to the manufacture's protocol (Sigma Aldrich). RNA amount and integrity was determined and analyzed using RNA stdsens chips (700-7153) and Experion automated electrophoresis station (Bio-Rad, France). All samples were of high RNA quality after electrophoresis on agarose FlashGel system (Lonza, France). $1 \mu \mathrm{g}$ of total extracted RNA was used to perform the Reverse Transcription (RT) reaction (IScript reverse transcription, 170-8840). Sybergreen real-time PCR was carried out in a final volume of $10 \mu 1$ per reaction containing: $5 \mu 1$ of neo-synthetized cDNA (diluted at 1/5), $0.2 \mu \mathrm{l}$ of primer pair at $10 \mu \mathrm{M}$ each (Sigma Aldrich and Integrated DNA Technologies) and $4.8 \mu 1$ of GOTaq ${ }^{\circledR}$ qPCR Master Mix (A6001, Promega, Madison, USA). All 
experiments were monitored in a CFX Real-Time system (Bio-Rad, Marnes-La-Coquelle, France). The expression of target genes (MuRF-1, MAFbx, TNF- $\alpha$ and IL-6) was normalized to the reference genes $18 \mathrm{~S}$ or HPRT1 and the relative expression was calculated using the $\Delta \Delta \mathrm{Ct}$ method. The following primer sequences were used:

Trim-63 (F: ACATGGACTACTTTA-CTCTGG and R: CATTGGTGGTTCTTTACCC); Fbxo32 (F: CTGAAAGTTCTTGAAGA-CCAG and R: GTGTGCATAAGGATGTGTAC);

Rn18S (F: CAGTTATGGTTCCTTTGGTC and R: TTATCTAGAGTCACCAA-GCC);

TNF- $\alpha$ (F: CCAGACCCTCACACTCAGATCA and R: CACTTGGTGGTTTGCTACGAC);

IL-6 (F: ACTTCCATCCAGTTGCCTTCT and R: GAATTGCCATTGCACAACTCT);

HPRT1 (F: ACGCCAGACTTTGTTGGATTT and R: CAGGACTCCTCGTATTTGCAG).

\section{Western blot analysis}

Total proteins were extracted from Gas muscles and tumor tissues in a lysis buffer containing 50 $\mathrm{mM}$ Tris- $\mathrm{HCl}, 10 \mathrm{mM}$ EDTA, 1\% SDS, 1\% NP-40, 0.25\% sodium deoxycholate, $50 \mathrm{mM} \mathrm{NaF}$, $100 \mu \mathrm{M}$ sodium orthovanadate and proteases inhibitors cocktail (Sigma P8340, $5 \mu \mathrm{l} / \mathrm{ml}$ ). The samples were homogenized using a Polytron homogenizer at $4^{\circ} \mathrm{C}$. Each sample was then incubated on ice for $30 \mathrm{~min}$ followed by $3 \times 10 \mathrm{~s}$ of sonication. The homogenates were transferred to microcentrifuge tubes and centrifugated at $12000 \mathrm{~g}$ for $12 \mathrm{~min}$ at $4^{\circ} \mathrm{C}$. The protein concentration of the supernatant was determined by a Lowry assay using a serial dilution of bovine serum albumin (BSA) to draw the standard curve. Samples were then diluted in SDS- 
PAGE sample buffer [50 mM Tris $\cdot \mathrm{HCl}, \mathrm{pH}$ 6.8, 2\% SDS, 10\% glycerol, 5\% $\beta$-mercaptoethanol, and $0.1 \%$ bromophenol blue], and heated $5 \mathrm{~min}$ at $95^{\circ} \mathrm{C}$. Samples containing $40-100 \mu \mathrm{g}$ of proteins were resolved on 10-15\% SDS-PAGE. The proteins were transferred at $240 \mathrm{~mA}$ for 90 min onto a $0.2-\mu \mathrm{m}$ nitrocellulose membrane. Membranes were blocked with 5\% BSA or nonfat dry milk in TBST (Tris-buffered saline/0.1\% Tween-20) for one hour at room temperature (RT). Membranes were incubated overnight at $4{ }^{\circ} \mathrm{C}$ with the appropriate primary antibodies: antiphospho-AKT (9271S), anti-AKT (9272S), anti-phospho-NFkB (p65) subunit (3033S), anti-NFкB (p65) subunit (8242S), anti-ubiquitin (3933S), anti-p21 (2947S) and anti-p27 (2552S) (1:1000; Cell Signaling, Ozyme, Saint Quentin-Yvelines, France); anti-catalase (sc-50508) and anti-HSC70 (sc-7298) (1:2000; Santa Cruz technologies, Santa Cruz, CA, USA); anti-MnSOD (ADI-SOD-110-F; 1:500; Enzo Life Sciences, Lyon, France) and anti-CuZnSOD (6F5; 1:2000; Novus Biologicals, Bio-techne, Lille, France); anti- $\alpha$-sarcomeric actin (A2172; 1:5000; Sigma Aldrich) . Blots were washed with TBST and incubated for one hour at RT with infrared dyeconjugated secondary antibodies (LI-COR, Lincoln, NE, USA). After washing, blots were scanned using the Odyssey Imaging System (LI-COR, Lincoln, NE, USA). Densitometry analysis of the bands was conducted using GS-800 Imaging densitometer and QuantityOne software. Phospho-specific signal was normalized to the total signal to estimate the ratio of activation.

\section{Enzyme Linked Immunosorbent Assay (ELISA)}

Plasma myostatin levels were detected using Quantikine ${ }^{\circledR}$ ELISA kit purchased from R\&D systems (DGDF80, R\&D systems Europe, Lille, France). Briefly, $20 \mu 1$ of mouse plasma samples were activated by adding $10 \mu \mathrm{l}$ of $1 \mathrm{~N} \mathrm{Hcl}$ and neutralized with $10 \mu 1$ of $1.2 \mathrm{~N} \mathrm{NaOH} / 0.5 \mathrm{M}$ 
HEPES. Then the $\mathrm{pH}$ of neutralized samples was measured to ensure that it is within 7.2 and 7.6. Plasma samples were added to a 96 wells plate pre-coated with capture monoclonal antibody specific to myostatin. A detection antibody linked to a peroxidase enzyme was next added to each well. Finally, a substrate solution was added and color developed in proportion with the amount of myostatin bound in the initial step. Color change was measured at $450 \mathrm{~nm}$ using a microplate reader. Plasma TNF- $\alpha$ concentrations were determined using a mouse TNF- $\alpha$ detection kit according to the manufacture's protocol (430907, LEGEND MAX ${ }^{\mathrm{TM}}$, BioLegend)

\section{Oxygen Radical Absorbance Capacity assay (ORAC)}

Total antioxidant capacity was measured by spectro-fluorometry. A mixture containing: $0.5 \mathrm{M}$ perchloric acid (Prolabo), $100 \mathrm{mM}$ PBS and $100 \mu \mathrm{L}$ of plasma was centrifuged at $3000 \mathrm{~g}$ for 5 min at $4^{\circ} \mathrm{C}$. The $\mathrm{pH}$ of the obtained supernatant was adjusted to $\sim 7$ with a solution of $5 \mathrm{M} \mathrm{NaOH}$ and $50 \mu 1$ of supernatant were added into each well in a 96-well plate. Then, $14 \mu \mathrm{M}$ of fluorescein (Fluka) and $17.2 \mathrm{mg} / \mathrm{ml}$ of 2,2'-azobis (2-aminopropane) dihydrochloride (AAPH) were dispensed, into each well. Fluorescence was recorded for $60 \mathrm{~min}$ at excitation and emission wavelengths of 485 and $530 \mathrm{~nm}$, respectively, using a microplate reader. Calibration solutions of Trolox were also tested to establish a standard curve.

\section{Protein carbonylation}

Analysis of protein carbonyl levels was performed using an oxyblot kit according to the manufacture's protocol. (S7150; Millipore, Île-de-France, France). Protein extracts (10 $\mu \mathrm{g})$ were derivatized with $1 \%$ DNPH for 15 min at RT and then separated on 12.5\% SDS-PAGE. After transfer, membranes were blocked with $1 \%$ BSA in PBST (Phosphate Buffered Saline/0.05\% 
Tween-20) and then incubated overnight at $4^{\circ} \mathrm{C}$ with anti-DNP primary antibody (1:100) supplied with OxyBlot kit. After washes, secondary IgG goat anti-rabbit antibody (IRDye 680; LI-COR, Lincoln, NE, USA) was added for one hour in the dark at RT. Membranes were scanned using Odyssey Infrared Imaging System.

\section{4-Hydroxy-2-nonenal analysis}

Detection of 4-hydroxy-2-nonenal (4-HNE) adducts, was performed as described previously [24]. Briefly, membranes were incubated in a solution of $250 \mathrm{mM}$ sodium borohydride in $100 \mathrm{mM}$ MOPS, for $15 \mathrm{~min}$ at RT, immediately after transfer. Then, were incubated overnight at $4^{\circ} \mathrm{C}$ with primary antibody, specific for 4-HNE, which was kindly provided by Pr. Luke Szweda (OMRF, Oklahoma City, OK, USA). Membranes were washed with PBST and incubated for one hour at RT with secondary IgG goat anti-rabbit antibody (IRDye 680; LI-COR, Lincoln, NE, USA). After washing, membranes were scanned using the Odyssey Imaging System.

\section{Statistical analysis}

Median survival was determined by the Kaplan-Meier method and analyzed by the log-rank test. Other results are presented as means \pm Standard Error Mean (SEM). Significance of intergroup differences was examined using Student t-test for tumor comparisons or One-way analysis of variance (ANOVA) for muscle and plasma comparisons. Normality and equal variance were checked before the statistical analysis was conducted. Significant main effects or interactions were further analyzed by the Fischer LSD post hoc test. If normality of the data was not present, the data were analyzed using an ANOVA on ranks, and further analyzed by the Dunn's test. For all statistical analyzes, the level of significance was set at $P<0.05$. 


\section{RESULTS}

\section{Antioxidant supplementation enhanced colon cancer cachexia development and caused premature death}

To assess the effect of antioxidant supplementation on cancer cachexia development, we supplemented C26-mice, an experimental model widely used to study cancer cachexia, with a mixture of antioxidants or PBS, as described above. Surprisingly, we found that body weight of supplemented animals (C26-Antiox) started to decrease at $10^{\text {th }}$ day post injection, whereas C26PBS mice presented significant body mass reduction only after 20 days post injection (Figure 1A). When mortality started to occur in C26-mice groups, body weight measures were no more taken into account in data interpretation, which explains why body weight measures were stopped at $13^{\text {th }}$ and $20^{\text {th }}$ days for C26-Antiox and C26-PBS mice, respectively. Here, we showed that antioxidant supplementation caused $50 \%$ and $100 \%$ of C26-mice deaths at 18 days and 22 days post injection, respectively. In comparison, only $20 \%$ of C26-PBS mice died after 22 days (Figure 1B). Furthermore, neither C26-PBS nor C26-Antiox mice developed anorexia since no change in food intake was observed in both groups compared to control group (Figure 1C). Based on various criteria of cancer cachexia development (see Materials and Methods), we found that all supplemented mice developed severe cachexia, while C26-PBS mice were distributed between mild, moderate and severe cachexia (Figure 1D). These results demonstrated that natural antioxidants enhanced colon cancer cachexia development and caused premature death in C26-mice.

\section{Cachexia-induced muscle wasting was not prevented with antioxidants}


Next, we investigated whether muscle wasting was modulated with antioxidants. As depicted in Figure 2C, both C26-PBS and C26-Antiox mice exhibited lower muscles weight compared to control mice (except for soleus). Remarkably, EDL and Gas muscles weight of C26-Antiox mice were significantly lower than those of C26-PBS mice $(6.6 \pm 1.3$ and $79.4 \pm 10.8 \mathrm{mg}$, respectively, vs. $8 \pm 1.4$ and $94.5 \pm 11.3 \mathrm{mg}, P<0.001$, Figure $2 \boldsymbol{C}$ ). Figure $2 \boldsymbol{A}$ shows EDL muscle sections stained for reticulin with the Gomori method. We observed that fibers diameter of both C26-PBS and C26-Antiox-mice were lower than control group $(29.8 \pm 5.8$ and $28.9 \pm 3.1 \mu \mathrm{m}$, respectively vs. $41.2 \pm 3.1 \mu \mathrm{m}, P<0.05$, Figure $2 B$ ). A hanging wire grip test was also performed to determine how C26 tumor and antioxidants affect animals' muscle strength. Interestingly, the impulse score decreased dramatically in C26-PBS and C26-Antiox mice (6.32 \pm 1.81 and $3.85 \pm$ 2.14 N.sec, respectively) compared to control $(18.47 \pm 7.11$ N.sec; Figure $2 \boldsymbol{D})$ at 22 days or when mice reached $20 \%$ of body weight loss. No difference in impulse score was observed between the three groups at $10^{\text {th }}$ days post-injection. Contrary to our speculations, antioxidant complements were unsuccessful to slow muscle wasting.

\section{Antioxidants suppressed Akt activation but failed to block ubiquitin-proteasome system induction}

Tumor Necrosis Factor- $\alpha$ (TNF- $\alpha$ ) and Myostatin (Mstn) are two mediators known to play a key role in the wasting process. We found that circulating TNF- $\alpha$ levels were up-regulated in both C26-PBS and C26-Antiox groups $(10.52 \pm 2.63$ and $7.5 \pm 2.23 \mathrm{pg} / \mathrm{mL}$ respectively, $P<0.001)$ compared to control $(2.17 \pm 0.34 \mathrm{pg} / \mathrm{mL}$; Figure $3 \boldsymbol{A})$. Whereas the relative expression of TNF- $\alpha$ and IL-6 transcripts in Gas remained unchanged between all three experimental groups (Figure 
S1). Counterintuitively, plasma Mstn levels were drastically decreased in C26-PBS compared to control $(16819 \pm 4283$ vs $41464 \pm 5418 \mathrm{pg} / \mathrm{mL})$. This decrease was more pronounced in C26Antiox $(10603 \pm 2523 \mathrm{pg} / \mathrm{mL}$; Figure 3B). Furthermore, we found that Mstn levels were positively correlated with Gas muscle mass $(\mathrm{r}=0.91, P<0.05)$. Gas muscles were used to perform western blotting and RT-qPCR analysis. Interestingly, Akt activation (ratio phospho-Akt/Akt total), a marker of protein synthesis, was down-regulated only in antioxidants-supplemented mice comparing to $\mathrm{C} 26$ and control $(-77 \%, P<0.05$, Figure $3 D)$. The phosphorylation of Nuclear Factor- $\kappa \mathrm{B}(\mathrm{NF}-\mathrm{\kappa B})$ on the p65 subunit was up-regulated in C26-PBS and C26-Antiox mice $(+141 \%$ and $+54 \%$ respectively, $P<0.001$; Figure $3 C)$. Although, p65 was phosphorylated to a lesser extend in supplemented comparing no-supplemented mice, the difference between both groups was not statistically significant. At the mRNA level the relative expression of MAFbx and MuRF-1, was flagrantly increased in both C26-PBS (7.6 and 4.7 fold, $P<0.001)$ and C26-Antiox (7.5 and 4.5 fold, $P<0.001$ ) comparing to control (Figure $3 E$ ). Accordingly, protein ubiquitination was increased in both groups of $\mathrm{C} 26(+29 \%$ and $+26 \%$, respectively, $P<0.05$; Figure $3 F$ ). Taken together, these data suggest that antioxidants decreased plasma Mstn levels, depressed Phospho-Akt expression and failed to prevent ubiquitin-proteasome system activation.

\section{Antioxidants exerted a pro-oxidant effect in skeletal muscle of C26 mice}

As shown in Figure $\mathbf{4 A}$, we observed that C26-Antiox mice exhibited higher carbonylated proteins levels compared to control animals $(+63 \%$; $P<0.001)$. Interestingly, no change was observed in C26-PBS mice when compared to control. Contrary to carbonylated proteins, no 
change in the protein content of 4-HNE, a marker of lipid peroxidation, was detected between the three experimental groups (Figure $4 \boldsymbol{B}$ ). Expression of the antioxidant enzymes, magnesium superoxide dismutase (MnSOD) and copper-zinc superoxide dismutase (CuZnSOD) remained unchanged between all groups of mice (Figure 4C). While, catalase expression was significantly higher in C26-PBS and C26-Antiox $(+70 \%$ and $+71 \%$ respectively; $P<0.01$; Figure $4 C)$ compared to control. These data indicate that antioxidant supplementation could up-regulate, in part, oxidative damage in skeletal muscle ongoing atrophy.

\section{C26-Antiox mice exhibited a paradoxical reduction in systemic antioxidant capacities}

As patients with colorectal cancer exhibit systemic OS $[25,26]$, we hypothesized that antioxidant supplementation in our experimental model of colon cancer could reduce systemic oxidative damages. We observed that C26-PBS and C26-Antiox mice exhibited systemic OS (Figure $5 \boldsymbol{B}$ and $C$ ), as evidenced by the increase of plasma carbonylated proteins content ( +85 and $+65 \%$ vs. control mice respectively; $P<0.01$, Figure $5 B)$ and $4-\mathrm{HNE}(+172.5$ and $+180 \%$ vs. control mice respectively; $P<0.001$, Figure 5C). However, no significant change in protein carbonyl and 4HNE content was detected between $\mathrm{C} 26$ and C26-Antiox mice. We next determined total antioxidant capacities in plasma, using the ORAC test. Total antioxidant capacities of C26-mice did not significantly differ from those of control mice $(1315 \pm 343$ vs. $1479 \pm 196 \mu$ mol eq Trolox/L). Unexpectedly, this parameter decreased drastically $(P<0.001)$ in C26-Antiox mice compared to control and C26-PBS mice (1479 \pm 196 vs. $823 \pm 174 \mu \mathrm{mol}$ eq Trolox/L, $P<0.001$ Figure 5A). These results suggest that the antioxidant cocktail decreased the total antioxidant capacities without impacting systemic OS in C26-mice. 


\section{Antioxidants accelerated tumor growth and reduced tumor lipid peroxidation}

To understand if the deleterious effects observed previously in supplemented mice were tumordependent, we analyzed the effects of antioxidant supplementation on tumor growth and OS. We observed that tumor weight did not differ between both C26-PBS and C26-Antiox mice (Figure 6A). Furthermore, Ki67 staining, a marker of proliferation rate, was significantly higher in C26Antiox mice compared to C26-PBS $(+14.3 \%, \mathrm{P}<0.01$; Figure $6 \boldsymbol{B}$ and $\boldsymbol{C})$. However, we highlight that tumor weights were early reached in C26-Antiox mice since these animals presented a median survival of 18 days, whereas this median was not reached in C26-PBS mice within 22 days when all C26-Antiox mice were died (see Figure 1B). These results suggest that antioxidant supplementation enhanced C26 tumor growth in our experimental model. In line with this hypothesis, we focused on tumor proliferation and cell cycle regulation. We found that the expression of $\mathrm{p} 21$ but not $\mathrm{p} 27$, two inhibitors of cell cycle, was down-regulated in tumor of C26Antiox mice when compared to C26-PBS mice $(-45 \%, P<0.05$, Figure 6D). To determine how antioxidant can modulate oxidative damage in tumor, we quantified 4-HNE and carbonylated proteins. No significant difference in carbonyled proteins content was denoted between C26-PBS and C26-Antiox mice (Figure 6E). We found that 4-HNE content was markedly lower in tumors of supplemented animals compared to C26-PBS mice (-66\%, P<0.001; Figure 6F). Ultimately, local inflammation within tumor seemed to be unaffected in response to antioxidant supplementation, as evidenced by the unchanged expression of TNF- $\alpha$ and IL- 6 at the mRNA level (Figure S1). All these data would finally support the paradigm, that antioxidants accelerate tumor proliferation and modulate OS profiles within tumor. 


\section{DISCUSSION}

Cancer cachexia is a devastating disorder that developed in $50-80 \%$ of patients with advanced stages of cancer. Common symptoms are: anemia, hypogonadism, systemic inflammation, respiratory failure, heart atrophy, altered liver metabolism, adipose tissue depletion and excessive loss of skeletal muscle [27-29]. Although muscle wasting, the key feature of cachexia, is mainly responsible for the death of many cancer patients, it remains a poorly understood mechanism. Several pieces of evidence suggest that OS is involved in the establishment and evolution of this catabolic process [30]. In the present study we demonstrated that supplementation with antioxidants reduced mice survival, failed to prevent muscle atrophy and promoted tumor growth in C26 tumor-bearing mice.

We found that antioxidants accelerated cachexia development and reduced life span in C26 mice. To our knowledge no studies have assessed the effects of antioxidant supplementation on the survival rate of cachectic animals. Nevertheless, recently, a meta-analysis concluded that the results of intervention studies with antioxidants, performed from 1966 till 2009, have no effects on colon cancer incidence and recurrence [31]. Even worse, they found that combination of $\beta$ carotene with other antioxidants was associated with an increase in mortality.

Elevated systemic levels of TNF- $\alpha$, Interleukine- 6 and Interferon- $\gamma$ have been reported in patients experiencing cachexia and in several rodent models of cancer cachexia [32-35]. There is considerable evidence that TNF- $\alpha$ plays a pivotal role in muscle loss during cancer cachexia. Thus transplantation of Chinese Hamster Ovary cells, transfected with human TNF- $\alpha$ gene, in nude mice produced a syndrome resembling to cachexia [36]. In our model the circulating levels 
of TNF- $\alpha$ were significantly higher in C26 mice supplemented or not with antioxidants. The unchanged expression of TNF- $\alpha$ within Gas muscles is not surprising, as usually skeletal muscle is not a major source of cytokines production during cachexia but rather undergo catabolism in response to tumor-derived cytokines. TNF- $\alpha$ induces the activation of NF- $\kappa \mathrm{B}$, leading to the induction of the ubiquitin-proteasome system [37]. We found that the p65 subunit of NF-kB was phosphorylated on the Ser536 residue, notably, in muscles of no-supplemented mice. The decrease of p65 phosphorylation levels observed in supplemented animals did not result in the reduction of MAFbx and MuRF-1 mRNA relative expression and protein ubiquitination, indicating that the ubiquitin-proteasome system was activated regardless the phosphorylation status of p65. Additionally the expression of IKB- $\alpha$, the specific inhibitor of NF- $\kappa \mathrm{B}$, remained unchanged in skeletal muscle of the three experimental groups (data not shown). This may suggest the existence of other compensatory mechanisms, than NF- $\kappa \mathrm{B}$ signaling, which promote proteasome system induction. Our interpretation is consistent with the findings of a recent report, showing that p65 binding to DNA is not required for the regulation of genes expression involved in the development of muscle atrophy in cachectic mice bearing C26 tumor [38]. Moreover, antioxidants have not only failed to slow the catabolic process but they, most likely, aggravated muscle wasting by suppressing Phospho-Akt expression, which is directly involved in protein synthesis. One striking finding of this study, was the flagrant decrease of plasma Mstn concentrations in cachectic C26 mice. Since Mstn is a negative regulator of muscle growth [39, 40], the loss of skeletal muscle in response to catabolic stimuli during cachexia could lead to a, protective, down-regulation of systemic Mstn levels. Moreover, as Mstn is mainly produced and secreted by skeletal muscle [41], it is expected that Mstn levels will decline in response to muscle 
mass decrease. This interpretation is coherent with our data showing a positive correlation between plasma Mstn concentrations and skeletal muscle mass. Such results are in line with a recent study reporting a decrease in plasma Mstn levels in cachectic patients with lung or colorectal cancer [42].

Redox imbalance and chronic OS were found in cancer patients, notably in those with colon cancer [43]. Others have found that protein degradation in skeletal muscle was mediated through the up-regulation of proteasome subunits and this was an OS-dependent mechanism [15]. Muscle oxidative damages were increased only in supplemented mice, without any change in the expression of MnSOD and CuZnSOD. On the other hand, catalase expression was up-regulated but seemed ineffective and insufficient to counteract muscle OS. We speculate that antioxidants provoked an unbalance in the redox state within muscle in favor of OS, thus creating a favorable microenvironment for the development and enhancement of muscle wasting. Furthermore, both C26 experimental groups exhibited systemic OS but the decrease in total antioxidants capacities was observed in supplemented mice only. This decrease, could be attributed to either, a prooxidant effect produced synergistically by the antioxidants cocktail or the consumption of antioxidants by another tissue, like tumor.

Although, tumor weights were similar in both C26 groups, this do not rule out the possibility that tumor of supplemented mice has developed faster, since they died earlier. Also it is plausible that the premature death of supplemented mice was tumor-dependent. Interestingly, we found that the percentage of tumor proliferating cells was greater in supplemented group and this was associated with a depression of p21 expression, suggesting that antioxidants have abolished potent stimuli 
for p21 induction and cell cycle arrest. All these elements plead in favor of an enhancement of tumor growth in supplemented mice. Interestingly, we found that 4-HNE deceased exclusively within tumor in response to antioxidant supplementation. Clinically, variable amounts of lipid peroxidation products were found in colorectal cancer tissues of patients [44] and the decrease in HNE levels was positively associated with tumor proliferation [45]. In order to provide explanations about the selective decrease of oxidative damage within tumor, we attempted to propose antioxidant compounds that could be potentially more problematical in our cachexia model. Our mixture contained mainly polyphenols, vitamin E and C. Recently, Sayin et al have elegantly demonstrated that supplementation with vitamin E accelerated lung cancer progression in mice, reduced ROS amounts within tumor and, the subsequent, oxidative damage level [46]. Accordingly, Yam and coworkers demonstrated, in a model of mice bearing Lewis Lung Carcinoma (LLC), that vitamin $\mathrm{E}$ and $\mathrm{C}$ reduced the anticancer activity of omega-3 enriched diet by decreasing in situ oxidation of fatty acids [47]. Thus, we speculate that vitamin E and C, wellknown to inhibit lipid peroxidation, could be potential candidates responsible for the decrease of 4-HNE content in C26 tumor of supplemented mice. Other major components of our antioxidant mixture were polyphenols, namely, catechins, resveratrol and quercetin. On the one hand supplementation with resveratrol does not affect tumor growth and muscle wasting in distinct models of cancer cachexia [48]. On the other hand, administration of either catechins or quercetin, into cachectic rodent bearing tumor, reduced the magnitude of muscle atrophy and tumor weights $[49,50]$. It should be highlighted that these studies focused mostly on muscle wasting but lacked direct analyzes on tumor proliferation and modulation of systemic and local OS. As ROS may exert a double-faced role in cancer [51], antioxidants could be beneficial in 
other experimental models, despite the deleterious effects observed in this study. For example, we have previously shown that dietary antioxidants decreased tumor oxidative damage and reduced proliferation in prostate cancer [24]. Thus, inhibition of OS could either enhance or slow tumor growth depending on tumor type/localization.

One of the limitations of our study was the identification of the antioxidant compound responsible for the acceleration of cachexia development. At the same time, we cannot deny the fact that using these antioxidants in combination, but not in an isolated manner, is perhaps behind the harmful effects observed in mice. We believe that the experimental model employed in the present study, could be more reflective to what happening clinically with cancer patients who privilege the use of an antioxidant cocktail, as they believe that these compounds are natural and safe. The usefulness of antioxidants supplementation in cancer and cancer cachexia remains questionable and data emerging from interventions studies are controversial and incoherent [5256]. The self-prescribe antioxidants in cancer patients is recurrent and starts to be an alarming phenomenon, especially when antioxidants are used randomly and inappropriately. More than $50 \%$ of patients with cancer, increase their consumption of antioxidants complements, without medical prescription, after diagnosis of cancer [57]. In the present study, we used an antioxidant cocktail available at the European market as "Over The Counter" medicament and doses given to mice were adjusted to be adequate with supplier's recommendations. Another important detail is that individual doses of each antioxidant compound were not ultra-physiologic comparing to the most of studies conducted on animals. The present study clearly indicates that the daily use of antioxidant complements in colon cancer cachexia reduced survival and enhanced cachexiaassociated complications in C26 mice. Patients with cancer, especially those with cachexia, may 
be more cautious and careful regarding the use of antioxidants, as the prescription of such compounds should be done under the credible advice of a nutritionist or cancer patient's physician.

\section{ACKNOWLEDGMENTS}

The authors thank Pascale Bellaud (H2P2 platform, University Rennes 1, Rennes), Dany Saligaut, Morgane Chevallier, Brice Martin and Erwan Salaun for technical help. The authors' responsibilities were as follows—AR, FD: designed the research; AR: had primary responsibility for obtaining ethical approval; MA, FD, LLO, AR: conducted the research; MA, FD, AR: interpreted the data; MA, FD: performed statistical analysis; MA drafted the manuscript; FD, AR: contributed to subsequent versions; AR: had responsibility for the final; and all authors: read and approved the final manuscript.

FUNDING: Mohamad Assi is a recipient of a PhD research fellowship $\left(n^{\circ} 2012 / 22\right.$ ) from the Brittany Region Council. This study was supported by CRITT santé Bretagne.

CONFLICT OF INTERREST: None declared. 


\section{REFERENCES}

[1] Tisdale, M. J. Mechanisms of cancer cachexia. Physiological reviews 89:381-410; 2009.

[2] Gullett, N. P.; Mazurak, V. C.; Hebbar, G.; Ziegler, T. R. Nutritional interventions for cancer-induced cachexia. Current problems in cancer 35:58-90; 2011.

[3] Fearon, K. C.; Voss, A. C.; Hustead, D. S.; Cancer Cachexia Study, G. Definition of cancer cachexia: effect of weight loss, reduced food intake, and systemic inflammation on functional status and prognosis. The American journal of clinical nutrition 83:1345-1350; 2006.

[4] Bachmann, J.; Heiligensetzer, M.; Krakowski-Roosen, H.; Buchler, M. W.; Friess, H.; Martignoni, M. E. Cachexia worsens prognosis in patients with resectable pancreatic cancer. Journal of gastrointestinal surgery : official journal of the Society for Surgery of the Alimentary Tract 12:1193-1201; 2008.

[5] Fearon, K.; Strasser, F.; Anker, S. D.; Bosaeus, I.; Bruera, E.; Fainsinger, R. L.; Jatoi, A.; Loprinzi, C.; MacDonald, N.; Mantovani, G.; Davis, M.; Muscaritoli, M.; Ottery, F.; Radbruch, L.; Ravasco, P.; Walsh, D.; Wilcock, A.; Kaasa, S.; Baracos, V. E. Definition and classification of cancer cachexia: an international consensus. The Lancet. Oncology 12:489-495; 2011.

[6] Baracos, V. E. Management of muscle wasting in cancer-associated cachexia: understanding gained from experimental studies. Cancer 92:1669-1677; 2001.

[7] Garcia-Martinez, C.; Agell, N.; Llovera, M.; Lopez-Soriano, F. J.; Argiles, J. M. Tumour necrosis factor-alpha increases the ubiquitinization of rat skeletal muscle proteins. FEBS letters 323:211-214; 1993.

[8] Eley, H. L.; Tisdale, M. J. Skeletal muscle atrophy, a link between depression of protein synthesis and increase in degradation. The Journal of biological chemistry 282:7087-7097; 2007.

[9] Llovera, M.; Carbo, N.; Lopez-Soriano, J.; Garcia-Martinez, C.; Busquets, S.; Alvarez, B.; Agell, N.; Costelli, P.; Lopez-Soriano, F. J.; Celada, A.; Argiles, J. M. Different cytokines modulate ubiquitin gene expression in rat skeletal muscle. Cancer Lett 133:83-87; 1998.

[10] Li, Y. P.; Chen, Y.; John, J.; Moylan, J.; Jin, B.; Mann, D. L.; Reid, M. B. TNF-alpha acts via p38 MAPK to stimulate expression of the ubiquitin ligase atrogin1/MAFbx in skeletal muscle. FASEB journal : official publication of the Federation of American Societies for Experimental Biology 19:362-370; 2005.

[11] Khal, J.; Wyke, S. M.; Russell, S. T.; Hine, A. V.; Tisdale, M. J. Expression of the ubiquitin-proteasome pathway and muscle loss in experimental cancer cachexia. British journal of cancer 93:774-780; 2005. 
[12] DeRuisseau, L. R.; Recca, D. M.; Mogle, J. A.; Zoccolillo, M.; DeRuisseau, K. C. Metallothionein deficiency leads to soleus muscle contractile dysfunction following acute spinal cord injury in mice. American journal of physiology. Regulatory, integrative and comparative physiology 297:R1795-1802; 2009.

[13] Jang, Y. C.; Liu, Y.; Hayworth, C. R.; Bhattacharya, A.; Lustgarten, M. S.; Muller, F. L.; Chaudhuri, A.; Qi, W.; Li, Y.; Huang, J. Y.; Verdin, E.; Richardson, A.; Van Remmen, H. Dietary restriction attenuates age-associated muscle atrophy by lowering oxidative stress in mice even in complete absence of CuZnSOD. Aging cell 11:770-782; 2012.

[14] Puig-Vilanova, E.; Rodriguez, D. A.; Lloreta, J.; Ausin, P.; Pascual-Guardia, S.; Broquetas, J.; Roca, J.; Gea, J.; Barreiro, E. Oxidative stress, redox signaling pathways, and autophagy in cachectic muscles of male patients with advanced COPD and lung cancer. Free radical biology \& medicine 79:91-108; 2015.

[15] Gomes-Marcondes, M. C.; Tisdale, M. J. Induction of protein catabolism and the ubiquitin-proteasome pathway by mild oxidative stress. Cancer letters 180:69-74; 2002.

[16] Servais, S.; Letexier, D.; Favier, R.; Duchamp, C.; Desplanches, D. Prevention of unloading-induced atrophy by vitamin E supplementation: links between oxidative stress and soleus muscle proteolysis? Free radical biology \& medicine 42:627-635; 2007.

[17] Jackson, J. R.; Ryan, M. J.; Alway, S. E. Long-term supplementation with resveratrol alleviates oxidative stress but does not attenuate sarcopenia in aged mice. The journals of gerontology. Series A, Biological sciences and medical sciences 66:751-764; 2011.

[18] Derbre, F.; Ferrando, B.; Gomez-Cabrera, M. C.; Sanchis-Gomar, F.; Martinez-Bello, V. E.; Olaso-Gonzalez, G.; Diaz, A.; Gratas-Delamarche, A.; Cerda, M.; Vina, J. Inhibition of xanthine oxidase by allopurinol prevents skeletal muscle atrophy: role of p38 MAPKinase and E3 ubiquitin ligases. PloS one 7:e46668; 2012.

[19] Sinha-Hikim, I.; Sinha-Hikim, A. P.; Parveen, M.; Shen, R.; Goswami, R.; Tran, P.; Crum, A.; Norris, K. C. Long-term supplementation with a cystine-based antioxidant delays loss of muscle mass in aging. The journals of gerontology. Series A, Biological sciences and medical sciences 68:749-759; 2013.

[20] Tanaka, Y.; Eda, H.; Tanaka, T.; Udagawa, T.; Ishikawa, T.; Horii, I.; Ishitsuka, H.; Kataoka, T.; Taguchi, T. Experimental cancer cachexia induced by transplantable colon 26 adenocarcinoma in mice. Cancer research 50:2290-2295; 1990.

[21] Fujimoto-Ouchi, K.; Tamura, S.; Mori, K.; Tanaka, Y.; Ishitsuka, H. Establishment and characterization of cachexia-inducing and -non-inducing clones of murine colon 26 carcinoma. International journal of cancer. Journal international du cancer 61:522-528; 1995. 
[22] White, J. P.; Baltgalvis, K. A.; Puppa, M. J.; Sato, S.; Baynes, J. W.; Carson, J. A. Muscle oxidative capacity during IL-6-dependent cancer cachexia. Am J Physiol Regul Integr Comp Physiol 300:R201-211; 2011.

[23] Ray, M. A.; Trammell, R. A.; Verhulst, S.; Ran, S.; Toth, L. A. Development of a mouse model for assessing fatigue during chemotherapy. Comparative medicine 61:119-130; 2011.

[24] Gueritat, J.; Lefeuvre-Orfila, L.; Vincent, S.; Cretual, A.; Ravanat, J. L.; GratasDelamarche, A.; Rannou-Bekono, F.; Rebillard, A. Exercise training combined with antioxidant supplementation prevents the antiproliferative activity of their single treatment in prostate cancer through inhibition of redox adaptation. Free radical biology \& medicine 77:95-105; 2014.

[25] Bhagat, S. S.; Ghone, R. A.; Suryakar, A. N.; Hundekar, P. S. Lipid peroxidation and antioxidant vitamin status in colorectal cancer patients. Indian J Physiol Pharmacol 55:72-76; 2011.

[26] Santiago-Arteche, R.; Muniz, P.; Cavia-Saiz, M.; Garcia-Giron, C.; Garcia-Gonzalez, M.; Llorente-Ayala, B.; Corral, M. J. Cancer chemotherapy reduces plasma total polyphenols and total antioxidants capacity in colorectal cancer patients. Mol Biol Rep 39:9355-9360; 2012.

[27] Dodson, S.; Baracos, V. E.; Jatoi, A.; Evans, W. J.; Cella, D.; Dalton, J. T.; Steiner, M. S. Muscle wasting in cancer cachexia: clinical implications, diagnosis, and emerging treatment strategies. Annual review of medicine 62:265-279; 2011.

[28] Argiles, J. M.; Busquets, S.; Felipe, A.; Lopez-Soriano, F. J. Molecular mechanisms involved in muscle wasting in cancer and ageing: cachexia versus sarcopenia. The international journal of biochemistry \& cell biology 37:1084-1104; 2005.

[29] Johns, N.; Stephens, N. A.; Fearon, K. C. Muscle wasting in cancer. The international journal of biochemistry \& cell biology 45:2215-2229; 2013.

[30] Mantovani, G.; Madeddu, C.; Maccio, A. Cachexia and oxidative stress in cancer: an innovative therapeutic management. Curr Pharm Des 18:4813-4818; 2012.

[31] Pais, R.; Dumitrascu, D. L. Do antioxidants prevent colorectal cancer? A meta-analysis. Rom J Intern Med 51:152-163; 2013.

[32] Balkwill, F.; Osborne, R.; Burke, F.; Naylor, S.; Talbot, D.; Durbin, H.; Tavernier, J.; Fiers, W. Evidence for tumour necrosis factor/cachectin production in cancer. Lancet 2:12291232; 1987.

[33] Matthys, P.; Dijkmans, R.; Proost, P.; Van Damme, J.; Heremans, H.; Sobis, H.; Billiau, A. Severe cachexia in mice inoculated with interferon-gamma-producing tumor cells. International journal of cancer. Journal international du cancer 49:77-82; 1991. 
[34] Strassmann, G.; Fong, M.; Freter, C. E.; Windsor, S.; D'Alessandro, F.; Nordan, R. P. Suramin interferes with interleukin-6 receptor binding in vitro and inhibits colon-26-mediated experimental cancer cachexia in vivo. The Journal of clinical investigation 92:2152-2159; 1993.

[35] Zhou, X.; Wang, J. L.; Lu, J.; Song, Y.; Kwak, K. S.; Jiao, Q.; Rosenfeld, R.; Chen, Q.; Boone, T.; Simonet, W. S.; Lacey, D. L.; Goldberg, A. L.; Han, H. Q. Reversal of cancer cachexia and muscle wasting by ActRIIB antagonism leads to prolonged survival. Cell 142:531$543 ; 2010$.

[36] Oliff, A.; Defeo-Jones, D.; Boyer, M.; Martinez, D.; Kiefer, D.; Vuocolo, G.; Wolfe, A.; Socher, S. H. Tumors secreting human TNF/cachectin induce cachexia in mice. Cell 50:555-563; 1987.

[37] Li, Y. P.; Reid, M. B. NF-kappaB mediates the protein loss induced by TNF-alpha in differentiated skeletal muscle myotubes. Am J Physiol Regul Integr Comp Physiol 279:R1165$1170 ; 2000$.

[38] Cornwell, E. W.; Mirbod, A.; Wu, C. L.; Kandarian, S. C.; Jackman, R. W. C26 cancerinduced muscle wasting is IKKbeta-dependent and NF-kappaB-independent. PloS one 9:e87776; 2014.

[39] Grobet, L.; Martin, L. J.; Poncelet, D.; Pirottin, D.; Brouwers, B.; Riquet, J.; Schoeberlein, A.; Dunner, S.; Menissier, F.; Massabanda, J.; Fries, R.; Hanset, R.; Georges, M. A deletion in the bovine myostatin gene causes the double-muscled phenotype in cattle. Nature genetics 17:71$74 ; 1997$.

[40] Grobet, L.; Poncelet, D.; Royo, L. J.; Brouwers, B.; Pirottin, D.; Michaux, C.; Menissier, F.; Zanotti, M.; Dunner, S.; Georges, M. Molecular definition of an allelic series of mutations disrupting the myostatin function and causing double-muscling in cattle. Mammalian genome : official journal of the International Mammalian Genome Society 9:210-213; 1998.

[41] Lee, S. J. Regulation of muscle mass by myostatin. Annual review of cell and developmental biology 20:61-86; 2004.

[42] Loumaye, A.; de Barsy, M.; Nachit, M.; Lause, P.; Frateur, L.; van Maanen, A.; Trefois, P.; Gruson, D.; Thissen, J. P. Role of activin a and myostatin in human cancer cachexia. The Journal of clinical endocrinology and metabolism 100:2030-2038; 2015.

[43] Obtulowicz, T.; Swoboda, M.; Speina, E.; Gackowski, D.; Rozalski, R.; Siomek, A.; Janik, J.; Janowska, B.; Ciesla, J. M.; Jawien, A.; Banaszkiewicz, Z.; Guz, J.; Dziaman, T.; Szpila, A.; Olinski, R.; Tudek, B. Oxidative stress and 8-oxoguanine repair are enhanced in colon adenoma and carcinoma patients. Mutagenesis 25:463-471; 2010. 
[44] Skrzydlewska, E.; Sulkowski, S.; Koda, M.; Zalewski, B.; Kanczuga-Koda, L.; Sulkowska, M. Lipid peroxidation and antioxidant status in colorectal cancer. World $J$ Gastroenterol 11:403-406; 2005.

[45] Barrera, G. Oxidative stress and lipid peroxidation products in cancer progression and therapy. ISRN oncology 2012:137289; 2012.

[46] Sayin, V. I.; Ibrahim, M. X.; Larsson, E.; Nilsson, J. A.; Lindahl, P.; Bergo, M. O. Antioxidants accelerate lung cancer progression in mice. Science translational medicine 6:221ra215; 2014.

[47] Yam, D.; Peled, A.; Shinitzky, M. Suppression of tumor growth and metastasis by dietary fish oil combined with vitamins $\mathrm{E}$ and $\mathrm{C}$ and cisplatin. Cancer chemotherapy and pharmacology 47:34-40; 2001.

[48] Busquets, S.; Fuster, G.; Ametller, E.; Olivan, M.; Figueras, M.; Costelli, P.; Carbo, N.; Argiles, J. M.; Lopez-Soriano, F. J. Resveratrol does not ameliorate muscle wasting in different types of cancer cachexia models. Clin Nutr 26:239-244; 2007.

[49] Wang, H.; Bian, S.; Yang, C. S. Green tea polyphenol EGCG suppresses lung cancer cell growth through upregulating miR-210 expression caused by stabilizing HIF-1alpha. Carcinogenesis 32:1881-1889; 2011.

[50] Camargo, C. A.; da Silva, M. E.; da Silva, R. A.; Justo, G. Z.; Gomes-Marcondes, M. C.; Aoyama, H. Inhibition of tumor growth by quercetin with increase of survival and prevention of cachexia in Walker 256 tumor-bearing rats. Biochem Biophys Res Commun 406:638-642; 2011.

[51] Schieber, M.; Chandel, N. S. ROS function in redox signaling and oxidative stress. Current biology : CB 24:R453-462; 2014.

[52] van Zandwijk, N.; Dalesio, O.; Pastorino, U.; de Vries, N.; van Tinteren, H. EUROSCAN, a randomized trial of vitamin $\mathrm{A}$ and $\mathrm{N}$-acetylcysteine in patients with head and neck cancer or lung cancer. For the EUropean Organization for Research and Treatment of Cancer Head and Neck and Lung Cancer Cooperative Groups. Journal of the National Cancer Institute 92:977986; 2000.

[53] Lesperance, M. L.; Olivotto, I. A.; Forde, N.; Zhao, Y.; Speers, C.; Foster, H.; Tsao, M.; MacPherson, N.; Hoffer, A. Mega-dose vitamins and minerals in the treatment of non-metastatic breast cancer: an historical cohort study. Breast cancer research and treatment 76:137-143; 2002.

[54] Watson, J. Oxidants, antioxidants and the current incurability of metastatic cancers. Open biology 3:120144; 2013.

[55] Mantovani, G.; Madeddu, C. Cyclooxygenase-2 inhibitors and antioxidants in the treatment of cachexia. Curr Opin Support Palliat Care 2:275-281; 2008. 
[56] Mantovani, G.; Maccio, A.; Madeddu, C.; Gramignano, G.; Serpe, R.; Massa, E.; Dessi, M.; Tanca, F. M.; Sanna, E.; Deiana, L.; Panzone, F.; Contu, P.; Floris, C. Randomized phase III clinical trial of five different arms of treatment for patients with cancer cachexia: interim results. Nutrition 24:305-313; 2008.

[57] Velicer, C. M.; Ulrich, C. M. Vitamin and mineral supplement use among US adults after cancer diagnosis: a systematic review. J Clin Oncol 26:665-673; 2008. 


\section{FIGURE LEGENDS}

Figure 1. Antioxidant caused premature death of C26-mice. A) Changes in body weight during the course of cachexia. B) Median of animal survival determined by the Kaplan-Meier method, results are expressed as the percentage of animal survival. C) Food intake measurements during the protocol. D) Classification of cachexia severity into "Mild, Moderate or Severe" based on total body weight loss and muscle atrophy. Data are mean \pm SEM ( $n=8-10 /$ group). d: statistical difference between control and C26-Antiox; e: statistical difference between control and C26-PBS.

Figure 2. C26 inoculation induced muscle wasting in both C26-PBS and C26-Antiox groups. A) EDL sections stained with the Gomori method, showing structure of individualized muscle fibers; view $\times 400$. B) Fibers diameter measurements. C) Skeletal muscle weights. D) Muscle strength. Three trials per animal were performed for each evaluation and the best time of latency was retained to calculate the holding impulse. Data are mean \pm SEM (n=8-10/group) a: statistical difference between control and C26-PBS; b: statistical difference between control and C26Antiox; c: statistical difference between C26-PBS and C26-Antiox.

Figure 3. Antioxidants suppressed Akt activation in skeletal muscle without impacting the ubiquitin-proteasome system induction. A) Plasma levels of TNF- $\alpha$. B) Plasma concentrations

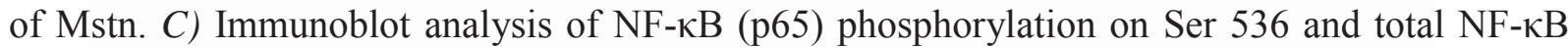
(p65) content. D) Immunoblot analysis of the phosphorylated form of Akt on ser 473 and total Akt. E) RT-qPCR analysis of the transcript levels of MAFbx and MuRF-1, normalized to the reference gene $18 \mathrm{~S}$. F) Immunoblot analysis of protein polyubiquitination content. (C-G) All 
these experiments were performed on gastrocnemius muscles. Data are mean \pm SEM ( $\mathrm{n}=8$ 10/group) a: statistical difference between control and C26-PBS; b: statistical difference between control and C26-Antiox; c: statistical difference between C26-PBS and C26-Antiox.

Figure 4. Antioxidant supplementation induced muscle oxidative stress. Immunoblot analysis of A) protein carbonyls content, B) 4-HNE content and C) the expression of antioxidant defense enzymes (MnSOD, CuZnSOD and Catalase). Expression of all proteins was normalized to actin, which was used as a load control. (A-C) Data are mean \pm SEM (n=8-10/group) a: statistical difference between control and C26-PBS; b: statistical difference between control and C26Antiox; c: statistical difference between C26-PBS and C26-Antiox.

Figure 5. Supplemented mice exhibited a reduced systemic antioxidant capacities. A) Plasma total antioxidant capacities measured using the ORAC test. Western blotting analysis of B) protein carbonyls and C) 4-HNE content in plasma. Data are mean \pm SEM (n=8-10/group) a: statistical difference between control and C26-PBS; b: statistical difference between control and C26-Antiox; c: statistical difference between C26-PBS and C26-Antiox.

Figure 6. Antioxidants accelerated tumor growth in C26-Antiox mice. A) Tumor weights. B) Ki-67 staining on tumor sections; view $\times 200$. C) Percentage of Ki-67 positive nuclei. D) Immunoblot analysis of p21 and p27 expression. Immunoblot analysis of E) protein carbonyls and F) 4-HNE content. All these experiments were performed on C26-tumors. Hsc-70 was used as a load control. Data are mean \pm SEM ( $n=8-10$ /group) a: statistical difference between control and C26-PBS; b: statistical difference between control and C26-Antiox; c: statistical difference between C26-PBS and C26-Antiox. 
Figure S1. Antioxidants did not affect pro-inflammatory cytokines expression within skeletal muscle and tumor. RT-qPCR analysis of the transcript levels of TNF- $\alpha$ and IL-6 within A) tumor and B) Gastrocnemius tissues, normalized to HPRT1 reference gene. The relative expression was calculated using the $\Delta \Delta \mathrm{Ct}$ method.

Table 1. Composition of antioxidant mixture

Nutritional information of antioxidant cocktail (mg/kg/day)

\begin{tabular}{|c|c|}
\hline \multicolumn{1}{|c|}{ Tea green extracts } & 11,53 \\
\hline Included polyphenols & 3,46 \\
\hline Curcumin & 8,65 \\
\hline Quercetin & 4,33 \\
\hline A-lipoic acid & 2,88 \\
\hline Oligomeric procyanidins & 2,88 \\
\hline \multicolumn{2}{|c|}{ Lutein } \\
\hline Piperin
\end{tabular}




\begin{tabular}{|c|c|}
\hline \multicolumn{1}{|c|}{ Resveratrol } & 0,14 \\
\hline Zinc & 1,08 \\
\hline Manganese & 0,14 \\
\hline Selenium & 0,0036 \\
\hline Vitamin A & 0,06 \\
\hline Vitamin C & 11,53 \\
\hline Vitamin E & 1,73 \\
\hline Vitamin B1 & 0,16 \\
\hline Vitamin B2 & 0,20 \\
\hline
\end{tabular}


Highlights

- Broad range of reactive oxygen species (ROS) is involved in the pathophysiology of cachexia-related muscle wasting

- We supposed that a combination of dietary antioxidants including: catechins, quercetin and vitamin $\mathrm{C}$ could target a large spectrum of ROS and narrow their detrimental effects

- In a model of C26 tumor-bearing mice, we showed that antioxidant supplementation, caused premature death, enhanced tumor growth and failed to prevent systemic inflammation and skeletal muscle atrophy

- The usefulness of antioxidant in cancer prevention remain questionable and arouses much controversy

- Our data indicate that antioxidant supplementation could be deleterious in colon cancer 
Fig. S1

A

Tumor

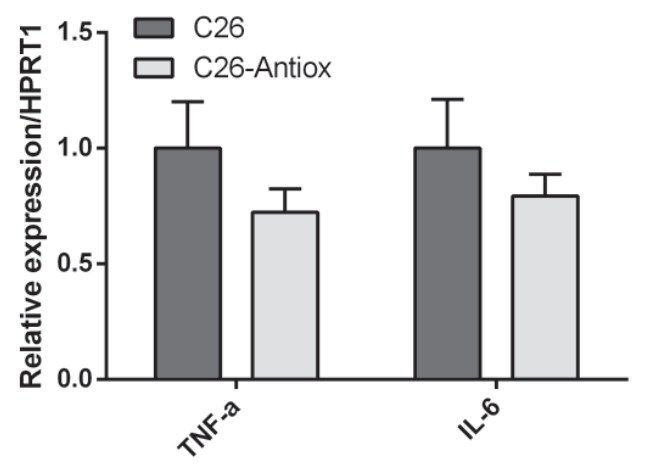

B

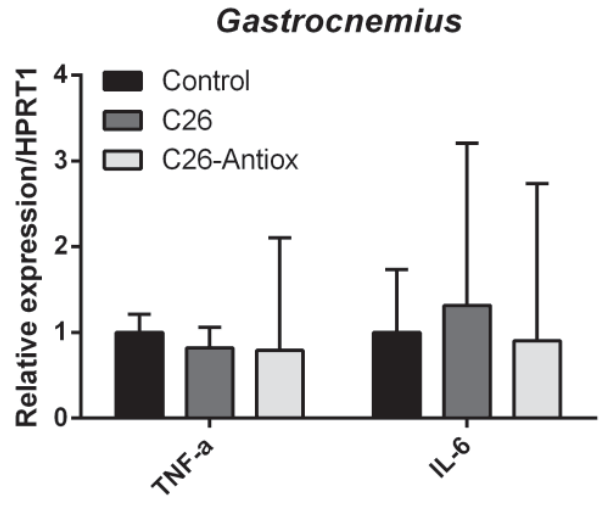

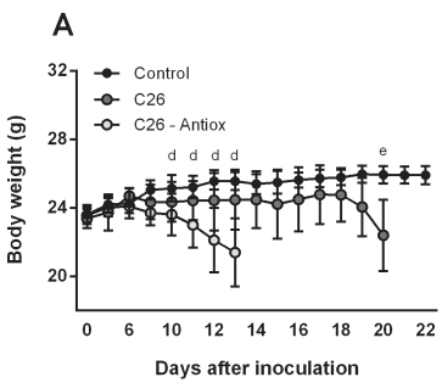

C

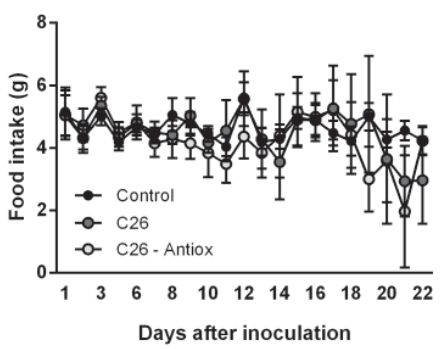

B

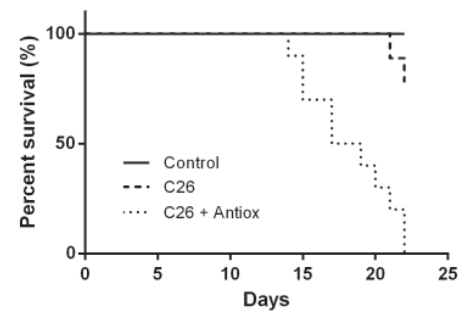

D

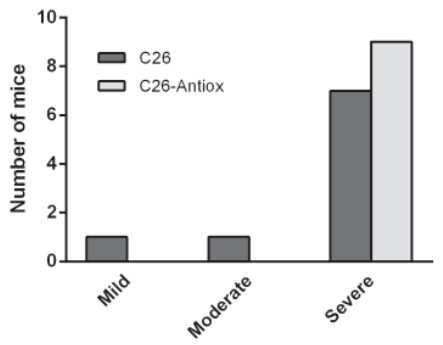


A

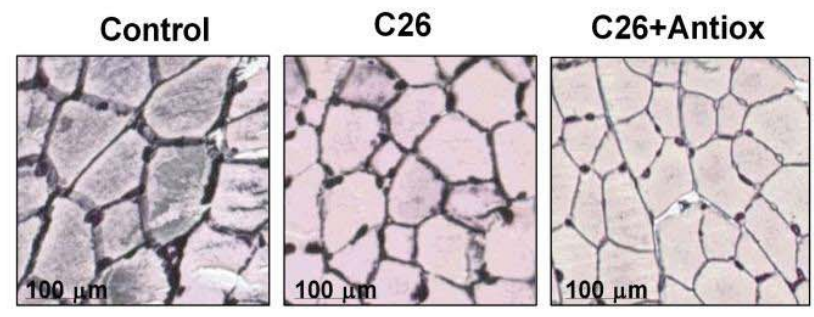

C

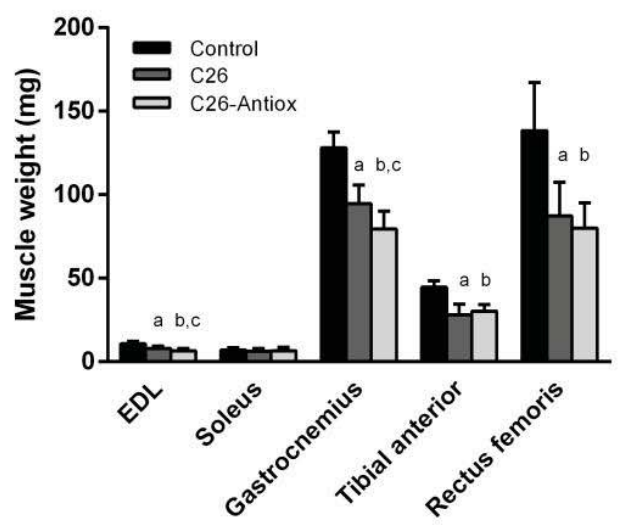

B

Fig. 2

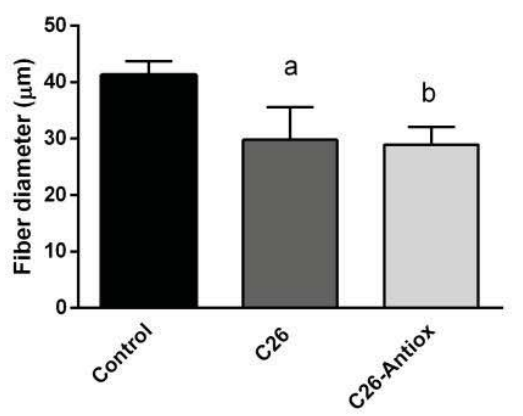

D

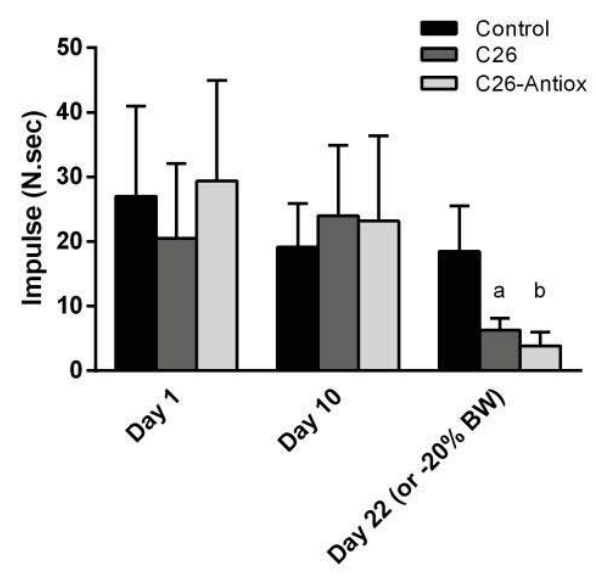




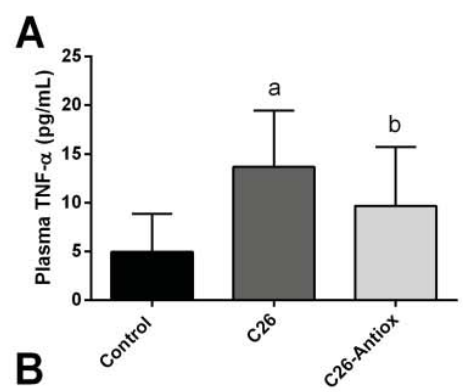

C
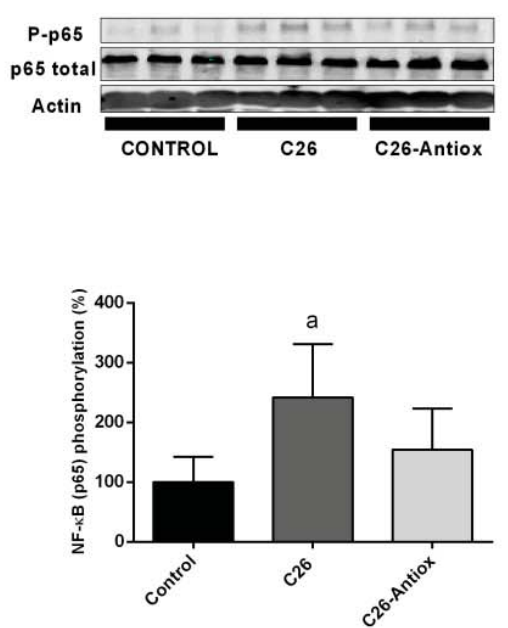

E

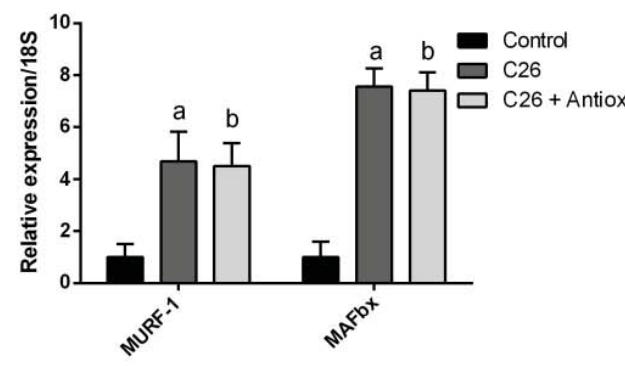

$\mathbf{F}$

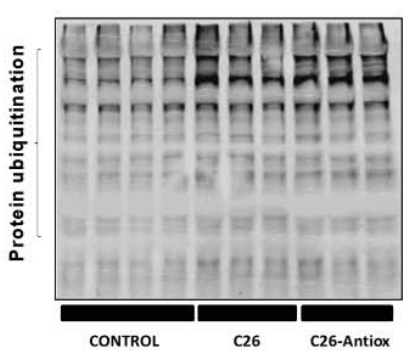

D

Fig. 3
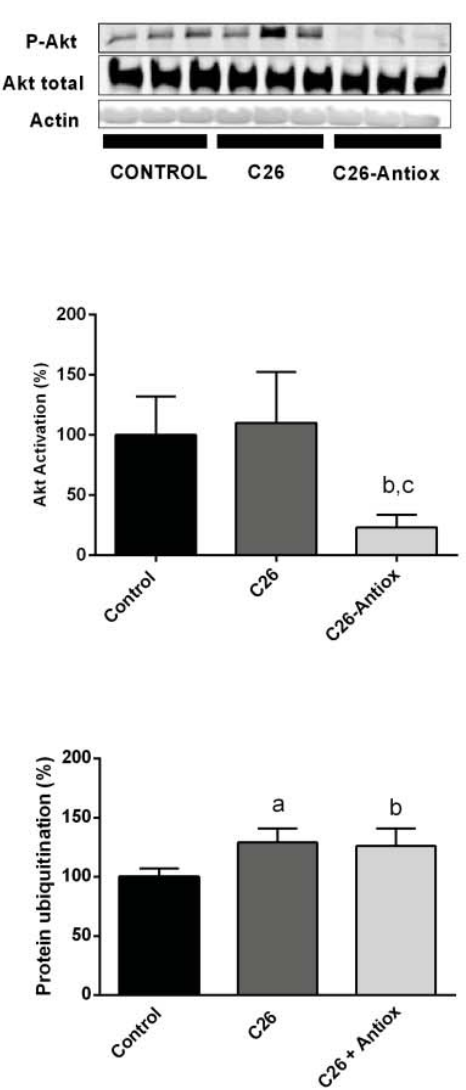


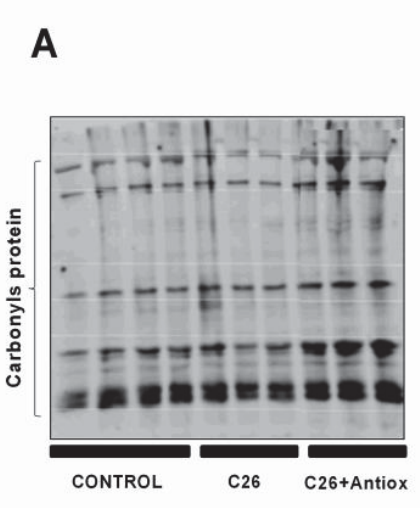

B
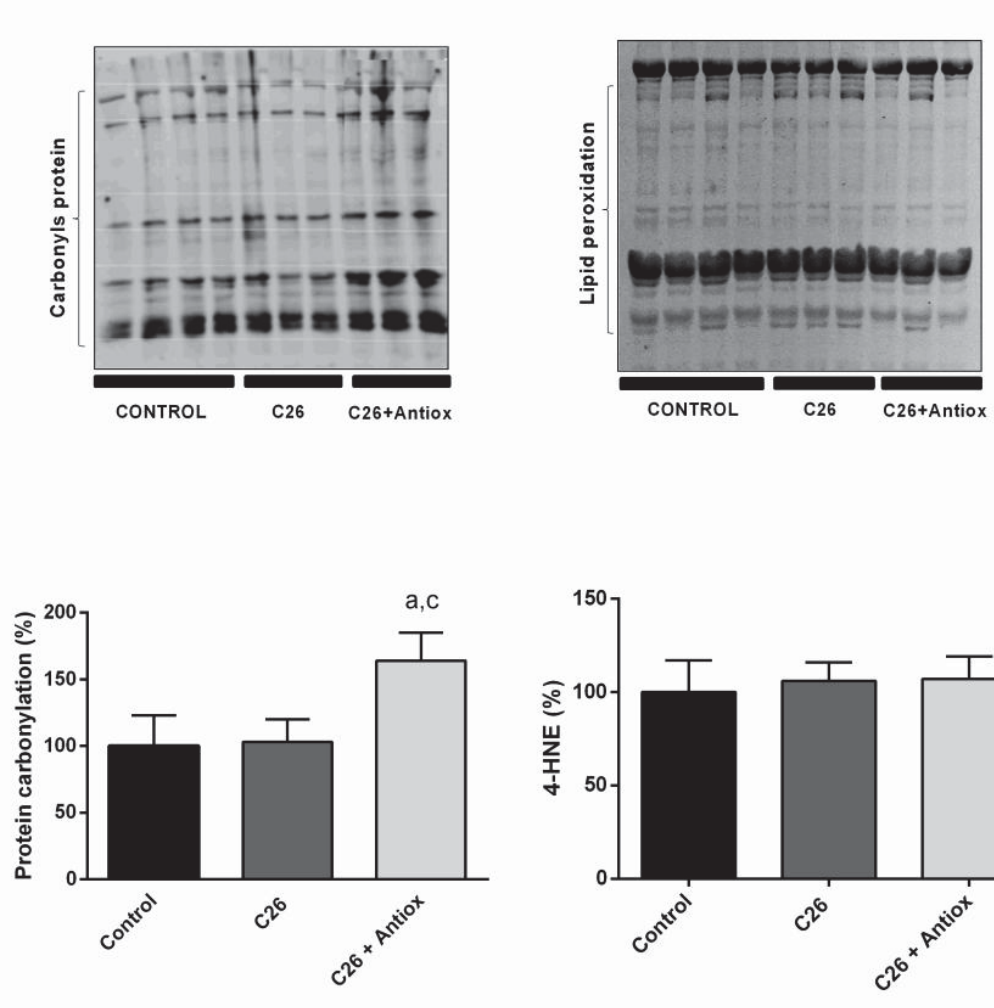

\section{C}
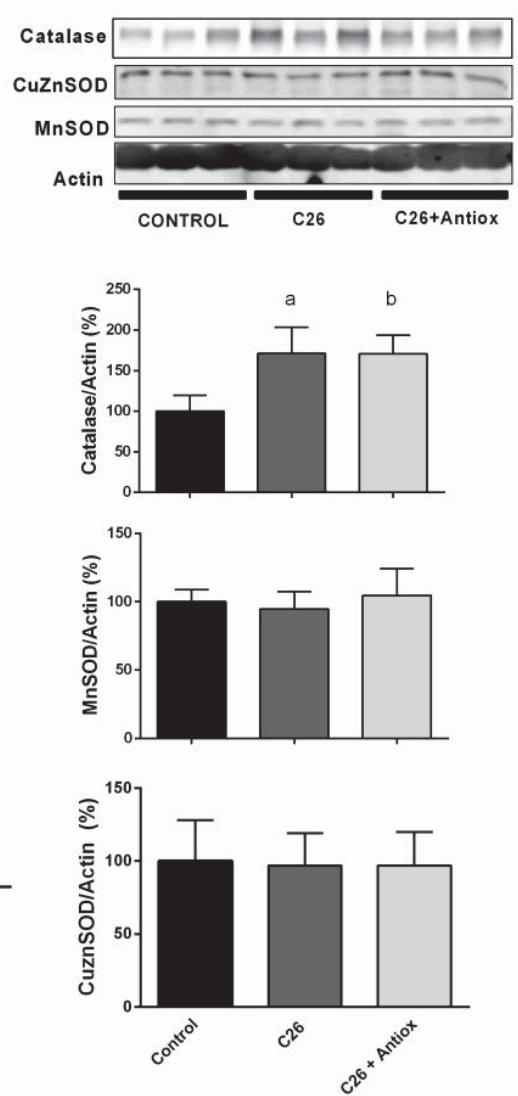

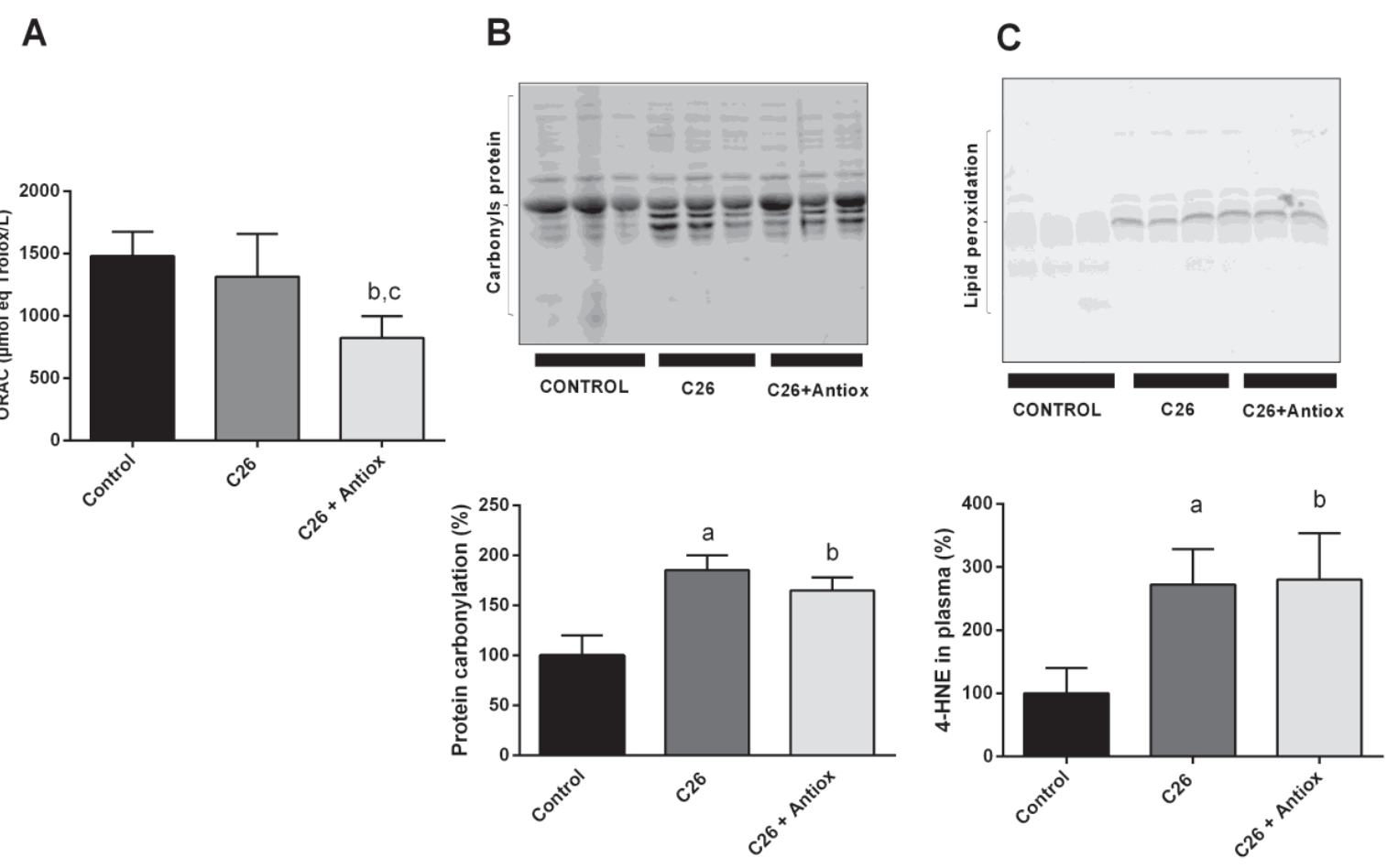
A B

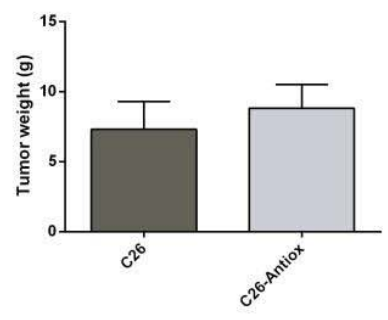

D
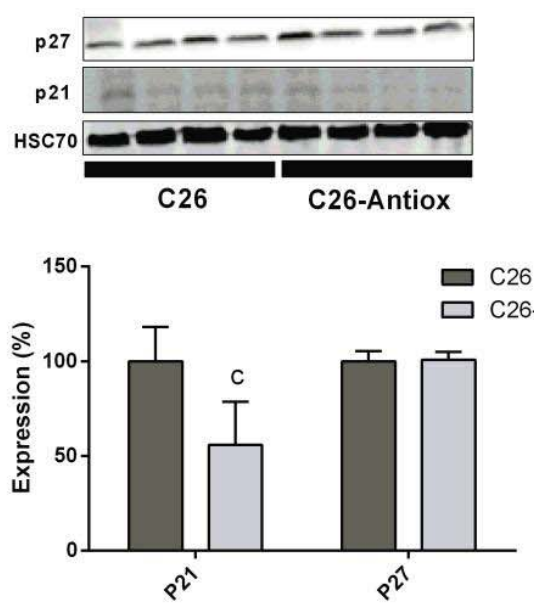

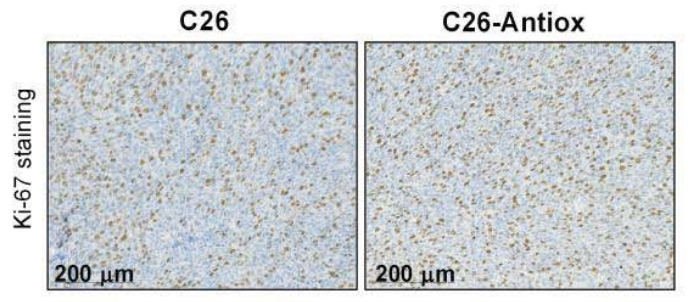

C

Fig. 6

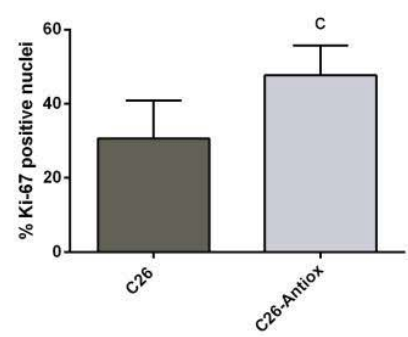

E
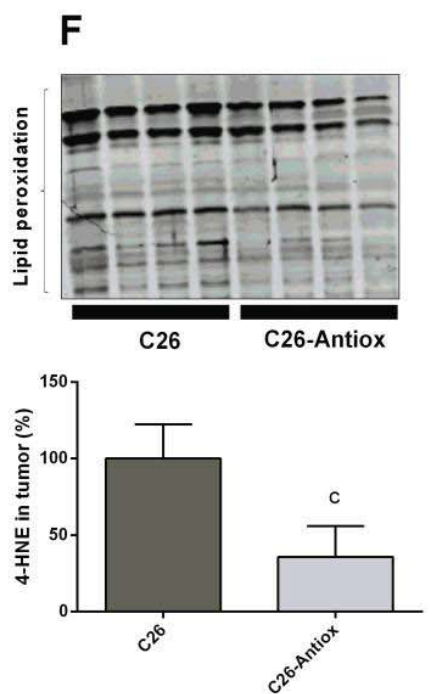


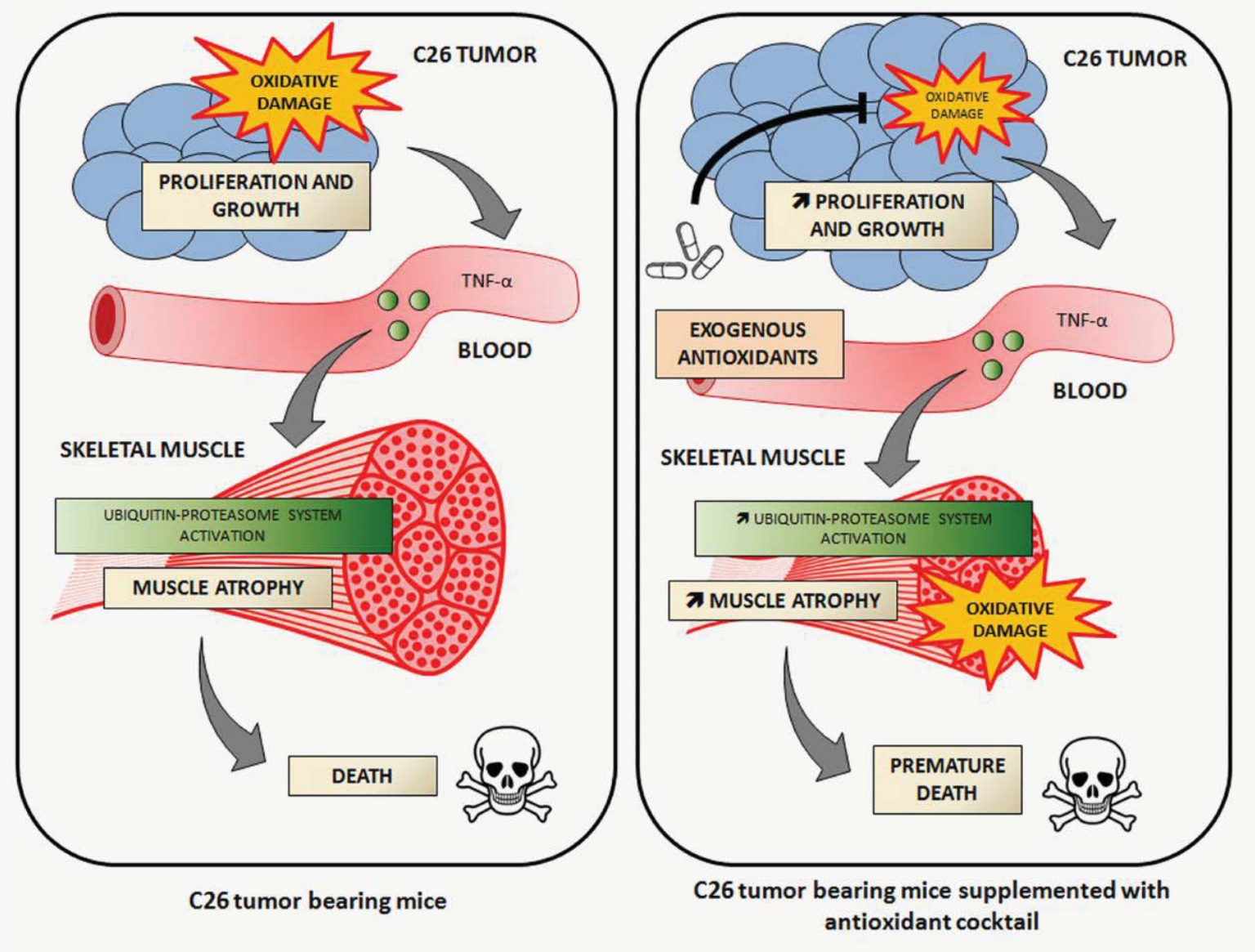

